\title{
Effect of High Hydrostatic Pressure, alkaline and combined treatments on corn starch granules metal binding: Structure, swelling behavior and thermal properties assessment
}

\author{
L. Deladino ${ }^{a, *}$, A. Schneider Teixeira ${ }^{a}$, F.J. Plou ${ }^{b}$, A.S. Navarro ${ }^{a, c}$, \\ A.D. Molina-García ${ }^{d}$ \\ a Centro de Investigación y Desarrollo en Criotecnología de los Alimentos (CIDCA), CONICET, Fac. Cs. Exactas \\ (UNLP), 47 y 116, La Plata 1900, Argentina \\ b Instituto de Catálisis y Petroleoquímica (ICP-CSIC), Cantoblanco, 28049 Madrid, Spain \\ c Fac. Ingeniería (UNLP), 1 y 47, La Plata 1900, Argentina \\ d Instituto Ciencia y Tecnología de Alimentos y Nutrición (ICTAN-CSIC), José Antonio Novais 10, 28040 Madrid, \\ Spain
}

\section{A R T I C L E I N F O}

\section{Article history:}

Received 25 August 2016

Received in revised form 12

December 2016

Accepted 4 January 2017

Available online 16 January 2017

Keywords:

Corn starch

High Hydrostatic Pressure

Alkaline treatments

Metal absorption

Zinc-magnesium

\begin{abstract}
A B S T R A C T
Modification of corn starch granules to transform them into carriers for molecules of nutritional interest was assayed by alkaline and high pressure treatments. Changes in the granular structure of starches were revealed by porosimetry and swelling power studies, while confocal microscopy evaluated the mode of disruption of the granules. Both alkali and high pressure treatments increased the number of pores in the granules while the combined procedures led to a central disruption and an increased deep pore number. The high pore volume found in alkali treated starches resulted in a high swelling power and created more binding sites to load high amounts of minerals, such as zinc and magnesium, as determined by atomic emission spectrometry. The extent of gelatinization process was affected differently in treated starches. The reduction in temperature and enthalpy, associated to high pressure granular starch suspensions, was moderated by the creation of new charged interactions due to alkali addition.
\end{abstract}

○ 2017 Institution of Chemical Engineers. Published by Elsevier B.V. All rights reserved.
1.

Introduction

High Hydrostatic Pressure (HHP) is an emerging non-thermal technology that, while meeting consumer requirements for fresher taste, minimally processed foods, can cause an important reduction of their microbial load. Although complete spore destruction solely by hydrostatic pressure has not been achieved and combination with heat or other physical or chemical treatments has been proposed (MolinaGarcía, 2002), the effect of pressure on vegetative microbial cells is considered as largely equivalent to that of heat pasteurization, as spores also survive this process (Considine et al., 2008; Drake et al. 1997; Tauscher, 1995). This technology involves the use of liquids (water is the usual pressure transmission medium) to convey pressure at 100-800 MPa (generally no less than $100 \mathrm{MPa}$ ) to treat food materials; most pressure levels used in commercial applications range from 200 to $600 \mathrm{MPa}$, depending on the product (Mújica-Paz et al., 2011).

Corn starch, a typical cereal origin product, can be completely gelatinized under High Hydrostatic Pressure treatment for a relatively short time at or near room temperature. Buckow et al. (2007) found that at $30^{\circ} \mathrm{C}$, maize starch was gelatinized completely after $30 \mathrm{~min}$ at $650 \mathrm{MPa}$. However, corn starch still retained some degree of integrity after being

\footnotetext{
* Corresponding author.

E-mail address: loredeladino@gmail.com (L. Deladino).

http://dx.doi.org/10.1016/j.fbp.2017.01.003

0960-3085/@ 2017 Institution of Chemical Engineers. Published by Elsevier B.V. All rights reserved.
} 
treated under $600 \mathrm{MPa}$, for $30 \mathrm{~min}$ at $20^{\circ} \mathrm{C}$ (Oh et al., 2008). Also, a pressure of $600 \mathrm{MPa}$ for $30 \mathrm{~min}$ led to a complete gelatinization of rice starch granules (Li et al., 2012). Meanwhile, when low pressure levels are employed, gelatinization is not complete and starch granular integrity and independence are partially preserved. Corn starch treated at $400 \mathrm{MPa}$, for 30-40 min at mild temperatures between room conditions and $40^{\circ} \mathrm{C}$, presents a mixed character preserving many of the native granule properties (granular integrity, reduced inter-granular interactions) while acquiring some of those of gelatinized starch (such as the partial substitution of internal hydrogen bridges by those with water) (Fernández et al., 2008; Pei-Ling et al., 2010). These last properties can be observed as a reduction in the enthalpy of gelatinization determined by differential scanning calorimetry (DSC) (Deladino et al., 2015). The decrease in enthalpy is attributed to the non-gelatinized starch fraction, which can also be related to its digestibility or resistant character (Papathanasiou et al., 2015).

Pores at the surfaces of intact starch granules, internal cavities at the granule hilum and channels connecting both, are architectural features that could influence granule reactions (Huber and BeMiller, 2000). Porous modified starches possess ligand slow-release characteristics compared with native starch, due to their adsorbent characteristics (Nagata et al., 2001; Weirong and Huiyuan, 2002). In a previous work, porosimetry analysis helped understand the effect of different high pressure treatments on corn starch (Deladino et al., 2015). Porosity of starch carriers was higher in HHP treated samples compared to the native starches, thus an increased exposed surface area suggested higher potential binding sites, which could be occupied by active compounds. The ability of these modified starch granules as carriers for small molecules of nutritional interest, such as oligoelements ions and antioxidant compounds has been successfully tested (Deladino et al., 2015; Fernández et al., 2008; Teixeira et al., 2015). The amount of yerba mate antioxidant compounds, an herbal aquous extract rich in chlorogenic acid (isomers and esters), caffeic acid and rutin, or metals ions that could be bound increased substantially over native starch with large differences in the incorporation level depending on the pressure treatment and ligand addition sequence (Deladino et al., 2015; Teixeira et al., 2015). It was shown that adding ligands to previously HHP treated starch is less efficient than to bind them to starch during pressure treatments (Deladino et al., 2015). However, the former method is considered more suitable for industrial application, as pressure treatment and binding become separate operations and the modified starch can be dried and stored before proceeding to binding.

Alkali-treated starches are promising as metal binders because of the partial ionization of hydroxyl groups. The treatment would turn alkali starch into a cation exchanger: the sodium counter ions have less affinity to the resultant starch than multivalent metal ions and are easily replaced. Tang and Liu (2012) studied the acidity of caustic digested starch and its role in starch adsorption on mineral surfaces. They measured the zeta potentials of starch digested with $0.25 \% \mathrm{NaOH}$, $0.25 \% \mathrm{KOH}$ or distilled water at room temperature and found that the isoelectric points of the causticized starch shifted towards more acidic $\mathrm{pH}$ than the native starch treated by distilled water. Moreover as the concentration of sodium hydroxide increases ( $0.15 \%, 0.25 \%$ and $0.5 \%$ ), the isoelectric points are increasingly lower. Thus, caustic treatment of starch caused the formation of surface functional groups such as carboxylic groups $(-\mathrm{COOH})$. The negative surface charge of the treated starch probably arose from the dissociation of protons from these functional groups, as also observed by Niemelä (1990).

Several studies of starches from different botanical origins contributed to the knowledge of alkali effects on starch granules structure and how these modifications could alter the swelling power, the gelatinization process and, as a consequence, the rheological properties of suspensions (Maher, 1983; Mondragón et al., 2004; Nor Nadiha et al., 2010; Roberts and Cameron, 2002; Wang et al., 2012; Yamamoto et al., 2006). However, works discussing the combined effects of alkali addition and high pressure on starches are limited (Wang and Copeland, 2012). In the present work, corn starch modified by alkaline treatment was compared with native and high pressure modified starches. In addition, a combination of the two procedures (alkali and pressure treatments) was analyzed. The efficiencies of the different treatments towards magnesium and zinc binding were explored, as well as several structural observations: porosimetry, swelling power, X-rays structure, calorimetric parameters and confocal microscopy granular image.

\section{Experimental}

\subsection{Materials}

Corn starch was purchased from Molinos Río de La Plata (Argentina). Sodium hydroxide $(\mathrm{NaOH})$, magnesium sulphate heptahydrate $\left(\mathrm{MgSO}_{4} \cdot 7 \mathrm{H}_{2} \mathrm{O}\right)$ and zinc sulphate monohydrate $\left(\mathrm{ZnSO}_{4} \cdot 1 \mathrm{H}_{2} \mathrm{O}\right)$ were all purchased from Panreac (Spain). Blue dextran $\left(\mathrm{MW}=2 \times 10^{6}\right)$ and fluorescein isothiocyanate (FITC) were both purchased from Sigma-Aldrich (USA). Nitric acid (65\%), chloridic acid (32\%), fluorhidric acid (40\%) and phosphoric acid (85\%) were all purchased from Merck (Germany).

\subsection{Preparation of starch carriers}

Carrier systems were native corn starch (S), alkaline corn starch (SA), high pressure treated starch (HPS) and alkalinehigh pressure treated starch (HPSA).

SA was obtained by suspending $10 \mathrm{~g} / 100 \mathrm{~mL}$ of corn starch in a $\mathrm{NaOH}$ solution with a final $\mathrm{NaOH}$ concentration of $0.1 \mathrm{~g} / 100 \mathrm{~g}$ deionized water (Milli- $\mathrm{Q}$ Millipore Inc. Bedford, MA, USA), under agitation for $1 \mathrm{~h}$ at $25^{\circ} \mathrm{C}$.

HPS was obtained by suspending $10 \mathrm{~g} / 100 \mathrm{~mL}$ of the native corn starch in deionized water (Milli-Q, Millipore Inc. Bedford, MA, USA), this suspension was treated using a High Hydrostatic Pressure (HHP) Pilot Food Processor (Stansted Fluid Power LTD. Model FP 571000:9/2C, UK) operated under $400 \mathrm{MPa}$, for $35 \mathrm{~min}$, at an initial vessel temperature of $38^{\circ} \mathrm{C}$ and reaching a final process temperature of $40^{\circ} \mathrm{C}$. These conditions were selected based on different assays performed in the lab (data not published) and conditions applied in previous works (Deladino et al., 2015; Fernández et al., 2008; Teixeira et al., 2015).

For HPSA samples, the SA suspensions were subjected to the HHP treatment as described above.

All treated starches were dried overnight in a convection oven at $35^{\circ} \mathrm{C}$ (Thermo Scientific, Germany). The dried samples were then crushed with a mortar and stored at room temperature in hermetic boxes.

\subsection{Preparation of starches loaded with minerals}

Mineral salt solutions, $\mathrm{MgSO}_{4}$ and $\mathrm{ZnSO}_{4}$ were dissolved at $0.05 \mathrm{M}$ concentration in $10 \mathrm{~g} / 100 \mathrm{~mL}$ S, SA, HPS and HPSA starch aqueous suspensions. All suspensions were agitated in an orbital shaker (Orbit Environ Shaker, Lab Instruments, USA) at $25^{\circ} \mathrm{C}$ and $180 \mathrm{rpm}$ for $15 \mathrm{~h}$. In the case of samples with both salts, $0.05 \mathrm{M}$ of each one was employed. Then the samples were centrifuged (Rolco, USA, $20 \mathrm{~min}, 300 \mathrm{~g}$ ) and the supernatants were discarded. Samples were dried in an oven at $30^{\circ} \mathrm{C}$. The obtained products were powdered in a mortar and stored in hermetic boxes. These samples will be named in general as "active starches"; the specific nomenclature with the detail of the applied treatments and the added minerals will be referred as: native $\left(\mathrm{S}_{\mathrm{Zn}}, \mathrm{S}_{\mathrm{Mg}}, \mathrm{S}_{\mathrm{ZnMg}}\right)$, alkali treated $\left(\mathrm{SA}_{\mathrm{Zn}}, \mathrm{SA}_{\mathrm{Mg}}, \mathrm{SA}_{\mathrm{ZnMg}}\right)$, HHP treated (HPS $\mathrm{Zn}_{\mathrm{Z}}, \mathrm{HPS}_{\mathrm{Mg}}, \mathrm{HPS}_{\mathrm{ZnMg}}$ ) and alkali-HHP treated (HPSA $_{\mathrm{Zn}}, \mathrm{HPSA}_{\mathrm{Mg}}, \mathrm{HPSA}_{\mathrm{ZnMg}}$ ) starches. 


\subsection{Characterization of starch carriers}

\subsubsection{Porosimetry}

A mercury porosimeter (AutoPore IV 9500, USA) was used to determine pore size and pore volume of the starches. Powder samples were dried at $80^{\circ} \mathrm{C}$ for $24 \mathrm{~h}$ and degassed for $5 \mathrm{~min}$ at 484 dynes/cm before analysis. Assays were carried out under controlled temperature conditions at $22^{\circ} \mathrm{C}\left( \pm 2^{\circ} \mathrm{C}\right)$. The highest intrusion pressure reached was $200 \mathrm{MPa}$. Pore sizes were calculated using the Washburn equation (Fornal et al., 2012):

$D=-\left(\frac{1}{P}\right) 4 \gamma \cos \varphi$

where $\mathrm{D}(\mathrm{nm})$ is the pore diameter and $\mathrm{P}(\mathrm{MPa})$ the applied pressure for mercury intrusion, assuming that pores were cylindrical in shape, the solid-liquid contact angle $(\varphi)$ was $141^{\circ}$ and the surface tension $(\gamma)$ of mercury was $484 \mathrm{dyn} / \mathrm{cm}$. The highest intrusion pressure reached was $200 \mathrm{MPa}$.

Intraparticle volume was calculated as the volume of mercury intruded after the last inflection point of the intrusion/extrusion curve (Beirão-da-Costa et al., 2011).

\subsubsection{Swelling power}

In this work blue dextran was used to determine the uptake of water of unswollen granules according to Tester and Morrison (1990), based on the observation that blue dextran does not penetrate swollen granules. To determine the starch swelling factor (SF, unitless), as a numerical indicator of its swelling power, starch $(100 \mathrm{mg})$ was weighed with a precision of $0.1 \mathrm{mg}$ into $10 \mathrm{~mL}$ screw cap tubes. Then $5.0 \mathrm{~mL}$ of water were added and the sealed tubes were incubated in a water bath with constant orbital shaking at $25^{\circ} \mathrm{C}$ for $15 \mathrm{~h}$, or at $75^{\circ} \mathrm{C}$ for $30 \mathrm{~min}$. After the incubation, $0.5 \mathrm{~mL}$ of blue dextran $(10 \mathrm{mg} / \mathrm{mL})$ was added and the contents were mixed by gently inverting the closed tubes several times. Samples were then centrifuged (Rolco, USA, $5 \mathrm{~min}, 500 \times \mathrm{g}$ ) and the absorbance of the supernatants $\left(A_{S}\right)$ were measured at $620 \mathrm{~nm}$ in a spectrophotometer (Shimadzu, UV-mini 1240, Japan). The absorbance of reference tubes $\left(A_{R}\right)$ that contained no starch was also measured. The swelling factor was referred to starch weight, corrected to $10 \%$ moisture and assuming a density of $1.4 \mathrm{~g} / \mathrm{mL}$; it was calculated as follows:

$\mathrm{SF}=1+\left\{(7700 / \mathrm{W})\left[\left(\mathrm{A}_{\mathrm{S}}-\mathrm{A}_{\mathrm{R}}\right) / \mathrm{A}_{\mathrm{S}}\right]\right\}$

where $\mathrm{W}$ is the initial weight of the starch (in milligrams).

\subsection{Characterization of active starch carriers}

\subsubsection{Determination of mineral salt content in starches}

Previously to the determination, starch samples were digested in acid media $\left(\mathrm{HNO}_{3}+\mathrm{HCl}+\mathrm{HF}+\mathrm{H}_{3} \mathrm{PO}_{4}\right)$ to transform them from solid to liquid, using a closed vessel in a high pressure digesting microwave (MW-AP Multiwave 3000, Anton Paar, UK). Then, liquid samples were streamed and atomized by argon plasma in an atomic emission spectrometer (ICP-OES) Optima 3300 DV Perkin Elmer (USA). The atomic stream emits a characteristic radiation depending on the element and its concentration is proportional to the intensity of the emitted signal. An external calibration method was used. Determinations were performed in duplicate.
2.5.2. Confocal laser scanning microscopy (CLSM)

Starch samples were analyzed after binding to a fluorescent label, fluorescein isothiocyanate (FITC) in $0.3 \mathrm{mg} / \mathrm{mL} \mathrm{pH}$ 9 buffer $\left(\mathrm{NaHCO}_{3} 50 \mathrm{mM}\right.$ and $\left.\mathrm{NaCl} 100 \mathrm{mM}\right)$, freshly prepared. Starch $(5 \mathrm{mg} / \mathrm{mL})$ was suspended in milli-Q water and $1000 \mu \mathrm{L}$ of the suspensions were stained by the addition of $40 \mu \mathrm{L}$ of FITC. The mixture was agitated in a vortex (Precytec, Argentina) and let to rest for $1.5 \mathrm{~h}$ in closed eppendorfs in darkness at room temperature before analysis. Starch granules were visualized using a LEICA TCS SP5 (Mannheim, Germany) inverted microscope equipped with $\mathrm{Ar}$ and HeNe laser, at excitation and emission wavelengths of 488 and $518 \mathrm{~nm}$, respectively. Images were acquired using a HCX PL APO CS $63.0 \times 1.40 / \mathrm{UV} /$ oil immersion objective with $1024 \times 1024$ pixel resolution, in a constant z-position. Software Leica Application Suite Advanced Fluorescence (LAS AF), version 2.2.1. build 4842 was employed in the image analysis.

\subsubsection{X-ray diffraction (XRD)}

XRD patterns of starch samples were obtained between $2 \theta=3-60^{\circ}$ in an X-ray diffractometer X'Pert Pro PANalytical Model PW3040/60 (Almelo, Netherland), using a $\mathrm{Cu} \mathrm{K} \alpha$ radiation $(\lambda=1.54186 \AA)$, at $40 \mathrm{kV}$ and $40 \mathrm{~mA}$. The crystalline fraction (CF) attributed to mineral incorporation was calculated as it was previously reported (Teixeira et al., 2015):

Mineral CF $=($ CFactive starch - CFcontrol starch $) * 100$

where CF (unitless) was calculated as the ratio between the absorption peaks and the total diffractogram area; the control starch depended on the starch carrier (S, SA, HPS or HPSA). The reported values corresponded to the average of two determinations.

\subsubsection{Differential scanning calorimetry (DSC)}

Before DSC analysis, starch samples were dispersed in water (20\% w/w on powder basis) $24 \mathrm{~h}$ to minimize hydration variability. Then, $15 \mu \mathrm{L}$ of suspensions were introduced in weighted aluminum pans, sealed and re-weighed. Determinations were performed with a DSC Q100 (TA Instruments, USA), calibrated with an Indium standard, at a heating rate of $10^{\circ} \mathrm{C} / \mathrm{min}$ from 25 to $110^{\circ} \mathrm{C}$. After analysis, pans were punctured and dried at $110^{\circ} \mathrm{C}$ to constant weight, to ensure accurate moisture and starch content determinations. Onset $\left(T_{0}\right)$ and peak temperature $\left(T_{p}\right)$ and gelatinization enthalpies $(\Delta H)$ were calculated from the thermograms following standard procedures (Universal Analysis Program, TA Instruments).

\subsection{Statistical analysis}

Analysis of variance (ANOVA) and Tukey's test for mean comparisons were performed with the software SYSTAT INC. (Evanston, USA). Unless indicated, a level of 95\% confidence $(\alpha=0.05)$ was used. Unless otherwise indicated, all assays were performed at least in triplicate.

\section{Results and discussion}

\subsection{Effect of alkali and high pressure treatments on the porosimetry of starch carriers}

The porosity of starch granules is considered to be a natural phenomenon resulting from the processes of granule 

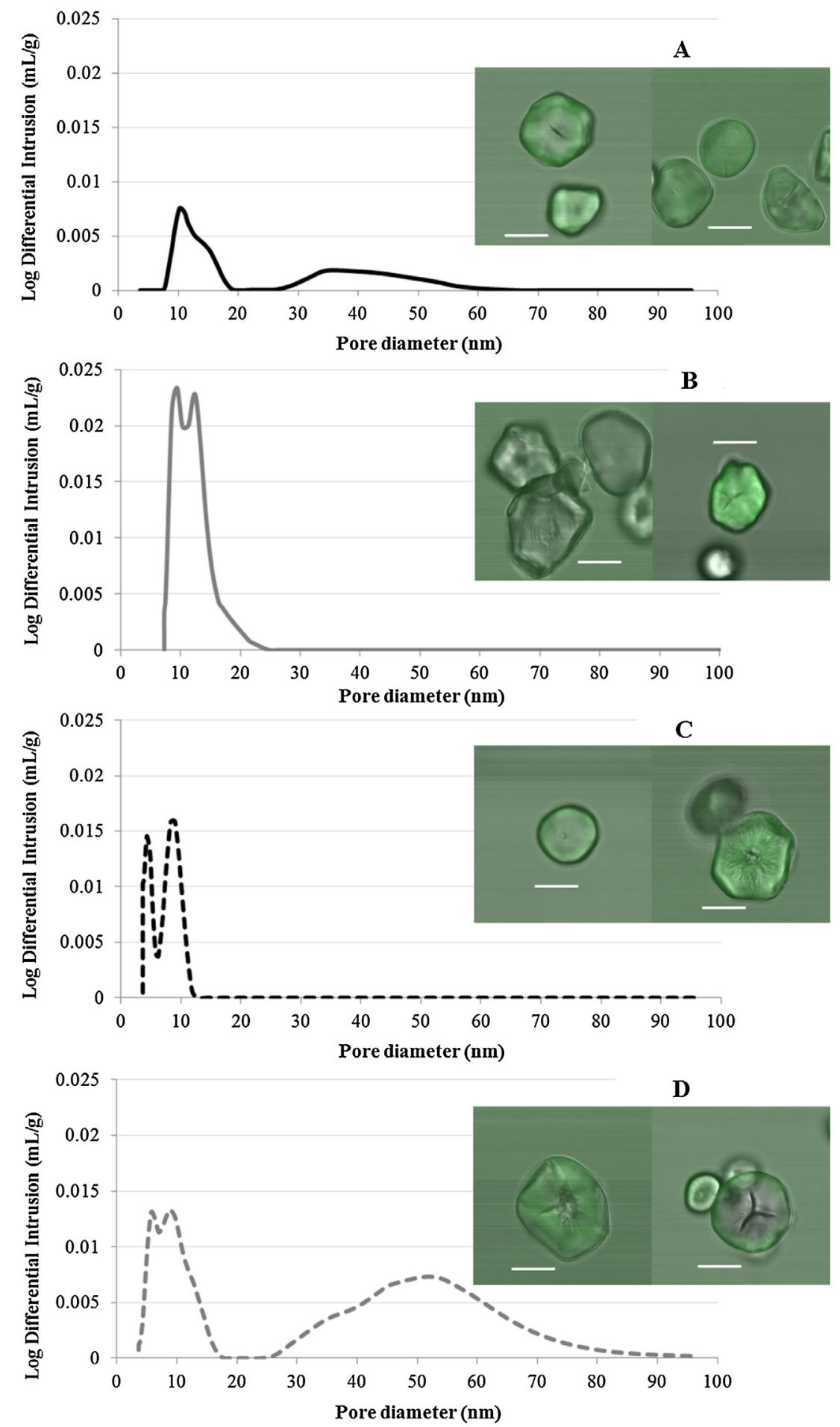

Fig. 1 - Pore diameter distribution of: native corn starch (S) (A), alkali treated starch (SA) (B), high pressure treated starch (HPS) (C) and high pressure-alkali treated corn starch (HPSA) (D), and corresponding overlay of channels of CLSM photomicrographs (inserts). Bars $=10 \mu \mathrm{m}$.

synthesis that take place during plant development (in storage organ tissues) and it plays an important role in water diffusion through the granule (Fornal et al., 2012). Pore size distributions for native (S) and HHP treated (HPS) starches and their corresponding alkali treated systems (SA and HPSA) are shown in Fig. 1. It can be observed that the different treatments applied to starches increased the number of pores in their granules, especially those of small diameter. Non-treated corn starch (S) showed a broad distribution of pore diameters ranging from 7 to $57 \mathrm{~nm}$, distributed in two size intervals, a smaller one between 7 and $19 \mathrm{~nm}$ with maxima number of pores at
11 and $15 \mathrm{~nm}$, and a larger size interval from 28 to $57 \mathrm{~nm}$ with a maximum at $34 \mathrm{~nm}$ (Fig. 1A). When an alkaline treatment was applied to corn starch (SA), a unimodal distribution $(7-25 \mathrm{~nm}$, with peaks at 9 and $12 \mathrm{~nm}$ ) was observed (Fig. 1B). Besides, the alkali media increased three times the pore volume compared to the untreated starch granules. According to the classification of IUPAC (Sujka and Jamroz, 2007), S starches showed mainly mesopores (diameters between 2 and $50 \mathrm{~nm}$ ) and macropores (diameters larger than $50 \mathrm{~nm}$ ); alkaline treatment increased the volume of mesopores in the starch granules but macropores were not detected (Fig. 1B). 
On the other hand, when a high pressure treatment was applied (HPS), a narrow profile, similar to that observed in SA, was obtained (Fig. 1C). However, the pore volume decreased and the number of small size pores was lower, ranging from 3 to $14 \mathrm{~nm}$ with maxima at 4 and $8 \mathrm{~nm}$. As shown in Fig. 1D, when the two treatments (high pressure and alkali) were combined (HPSA), a bimodal distribution similar to the $\mathrm{S}$ samples (Fig. 1A) was observed. A lower size interval at 3-17 nm (maxima at 6 and $10 \mathrm{~nm}$ ) and a wider larger size interval at $26-87 \mathrm{~nm}$ (maximum at $52 \mathrm{~nm}$ ) were obtained as a result of the combined treatments (Fig. 1D). These observations would suggest a higher extent of gelatinization in HPSA granules, as both the small and large size pores increased in number compared to the native granules (S). Even more, the larger size pores reached diameters that corresponded to macropores and their pore volume was 4 -fold higher.

Confocal laser scanning micrographs show some of the internal starch granule features (Fig. 1 inserts). Both alkaline (SA) and high pressure (HPS) treatments increased the presence of visible deep and wide pores where the dye can penetrate and accumulate. HPSA, as a result of the combined effect of the two treatments, showed central granule disruption and an increased deep pore number (Fig. 1D insert). These results are in good agreement with the porosimetry data described before. The presence of natural pores and cavities of corn starch granules would facilitate the diffusion of the alkali solution into them (Nor Nadiha et al., 2010), thus generating larger and deeper pores. These changes in the granular structure, enhanced by the additional high pressure treatment, would favor more binding sites to include active compounds.

\subsection{Swelling power of granules affected by the starch treatments}

The swelling power of starch samples was studied at $25^{\circ} \mathrm{C}$ during $15 \mathrm{~h}$ under agitation, to discard possible alterations in their microstructure along the immersion period associated to the treatments. At this temperature no effect was observed on SF for none of the starch carriers (data not shown). However, at $75^{\circ} \mathrm{C}$ the applied treatments affected the swelling power of native corn starch granules $(\mathrm{SF}=8.23 \pm 1.38)$ and increased values of this parameter were obtained for treated starches (SF $=15.48 \pm 2.27$ for HPS, $22.70 \pm 1.54$ for HPSA and $32.26 \pm 0.13$ for $\mathrm{SA}$ ). This order on the swelling factors of starches: $\mathrm{S}<\mathrm{HPS}<\mathrm{HPSA}<\mathrm{SA}$ correlates well with the porosimetry studies shown in Fig. 1. The higher pore volume found in SA starches would allow a higher swelling of their granules. According to Nor Nadiha et al. (2010), the increase in swelling power of alkali treated starches can be attributed to the disruption of the amorphous region of the granule, which presumably reduces the restraining effect of amylose, allowing the granule to swell more freely. However, in contrast to heat gelatinization, pressurized starch granules remain intact or just partly disintegrated and the solubilization of amylose is rather poor. It has been assumed that the crystalline components are prevented from melting since the amylopectin in the granule is stabilized by the still present amylose (Knorr et al., 2006). The differences in swelling power of the starch carriers can provide the food industry with a variety of ingredients, for example, foods with different viscosity requirements, such as soups and juices or spreading pastes. High Hydrostatic Pressure treated starch-rich foods have been industrially developed, such as an oven-cooked rice and instant cookedrice cereals successfully accepted by Japanese consumers and
Table 1 - Mineral content of bioactive carriers: corn starch (S), alkali treated starch (SA), high pressure treated starch (HPS) and high pressure-alkali treated corn starch (HPSA). Maximum standard deviation was 0.0009 for $\mathrm{Zn}$ and 0.00004 for $\mathrm{Mg}$.

\begin{tabular}{llccc} 
Starch & \multicolumn{3}{c}{ Mol mineral/100 g starch } \\
\cline { 2 - 5 } & $\mathrm{Zn}$ & $\mathrm{Mg}$ & \multicolumn{2}{c}{$\mathrm{Zn}+\mathrm{Mg}$} \\
\cline { 3 - 5 } & & & $\mathrm{Zn}$ & $\mathrm{Mg}$ \\
\hline $\mathrm{S}$ & 0.0043 & 0.0040 & 0.0049 & 0.0042 \\
$\mathrm{SA}$ & 0.0367 & 0.0405 & 0.0398 & 0.0370 \\
HPS & 0.0205 & 0.0250 & 0.0069 & 0.0084 \\
HPSA & 0.0323 & 0.0198 & 0.0067 & 0.0029 \\
\hline
\end{tabular}

the traditional rice cakes (omochi) and a special kind of omochi, which contains herbs with a natural color, smell, and taste, and this is now commercialized (Hayashi, 2005). Besides, the suitability of starch modified by HHP for different industrial applications has been repeatedly reported, especially mentioning the changes induced by pressure in starch enzymatic, gelatinization and retrogradation behavior, as well as in its structure, swelling power and flowability (Jobling, 2004; Nasehi and Javaheri, 2012).

\subsection{Loading of minerals to different starch carriers}

The amount of metal ions bound to starch granules determined by atomic emission spectrometry is shown in Table 1. Overall, higher amounts of minerals were detected in alkali treated starch (SA) in both cases each metal by separate or both metals applied together. While native starch (S) bound a similar magnesium and zinc content, even when both metals were added at the same time, the metal incorporation level was very low when compared with treated samples. Alkaline treatment favored a dramatic increase in binding of both metallic ions, nearly ten-fold. For magnesium and zinc added separately, the pressure-treated starch (HPS) also showed an increase in metal union, but more moderate (8-fold), as well as for the pressure and alkaline-treated sample (HPSA), which showed a higher binding efficiency for zinc than for magnesium. The results showed in Table 1 for each metal separately followed the same order of swelling power studies, which agreed with more sites for binding active compounds found in treated starches (Fig. 1).

A noticeable behavior was observed for HHP treated samples when minerals were incorporated together: for both HPS and HPSA, the loaded amounts of minerals were significantly lower in comparison with that bound for the same starch carrier, but with only one mineral (Table 1). As it was observed in previous studies, HPS starch bound a much more modest metal amount of the two metals than that united in separate treatments (Teixeira et al., 2015). The HPSA starch confirmed this trend and, for $\mathrm{Mg}$, the bound amount was even less than that measured for the native sample. A possible explanation could be the difference in hydration sphere of zinc and magnesium ions. In the case of small cations with higher charge like magnesium, the hydration sphere is bigger than the corresponding to the less charged sodium but also to zinc (Bock et al., 1995).

The loading of minerals to starch carriers was also analyzed by confocal laser scanning microscopy (Fig. 2). Micrographs of HPSA samples showed a higher level of penetration of the FITC dye (right column), which can be related to a larger 


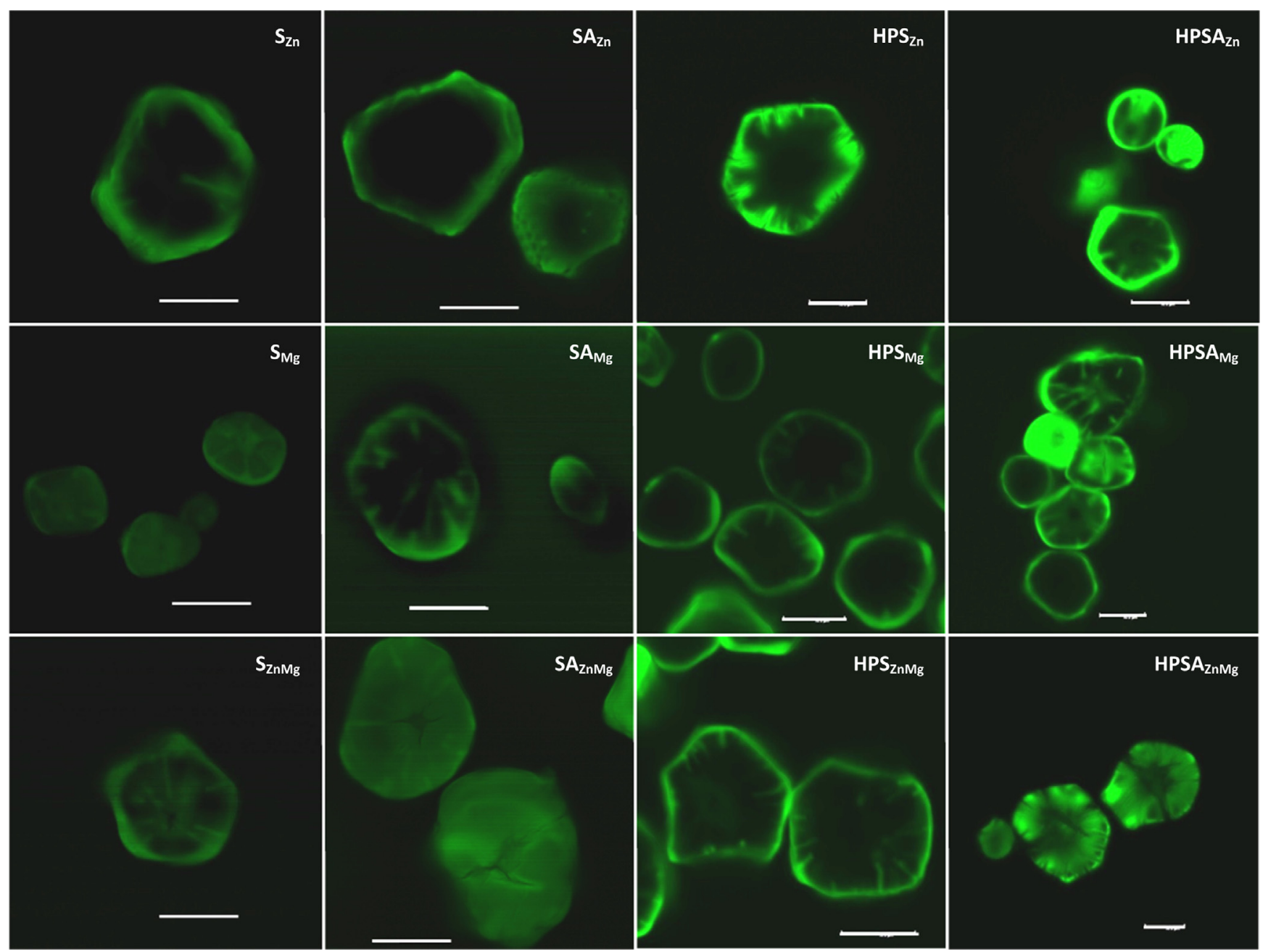

Fig. 2 - CLSM laser scanning photomicrographs of corn starch granules. Carriers with $\mathrm{Zn}$ in first line, carriers with Mg in second line, and carriers with both minerals together ( $\mathrm{Zn}$ and $\mathrm{Mg})$, in third line. Bars $=10 \mu \mathrm{m}$.

number of pores observed in these treated starches (Fig. 1). CLSM analysis revealed that the mode of disruption of the granule was very different for alkali and HHP treated starches (SA and HPS). In samples treated only by HHP (HPS $\mathrm{Zn}, \mathrm{HPS}_{\mathrm{Mg}}$, and $\mathrm{HPS}_{\mathrm{ZnMg}}$ ) the concentric structure of the granule (growth rings) remains close to the original, with a dyed circular center where channels penetrating from the surface end. Whereas, alkali treatment led to a hard cross rupture located at the hilum, denoting a greater extent of modification, in accordance with its higher pore volume and size (Fig. 1). This effect was maximized in $\mathrm{SA}_{\mathrm{ZnMg}}$ and $\mathrm{HPSA}_{\mathrm{ZnMg}}$ samples.

\subsection{Crystalline fraction by X-ray diffraction of active starches}

X-ray diffraction (XRD) patterns of starch granules are characterized by sharp peaks associated with the crystalline diffraction and an amorphous zone. The influence of HHP and alkali treatments on the crystalline structure of starch granules is shown in Fig. 3. The XRD patterns of SA and HPSA carriers showed a typical A-type XRD pattern with characteristic peaks at $2 \theta: 15.3,17.1,18.2,20.3$ and 23.5. These patterns matched with those observed for native and HHP treated starch studied before denoting no peaks of B-type pattern. With respect to the active starches, only a few characteristic peaks of salts were observed. A peak at $20.262 \theta$ for zinc sulphatehexahydrate (JCPDS-International Centre for Diffraction

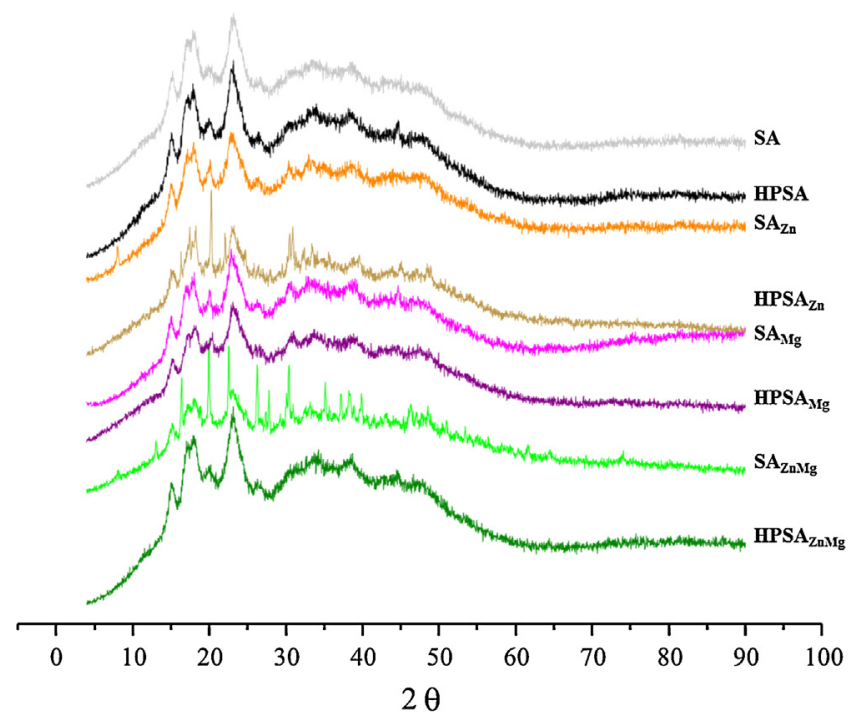

Fig. 3 - X-ray diffraction patterns of alkaline treated (SA) and alkaline-high pressure treated (HPSA) starch with minerals.

Data; Spiess and Gruehn, 1979; Teixeira et al., 2015; Walenta, 1978) was observed in $\mathrm{SA}_{\mathrm{ZnMg}}$ and $\mathrm{HPSA}_{\mathrm{Zn}}$, which agrees with the amounts of metal detected (Table 1). In the same samples, peaks corresponding to tetrahydrated zinc and magnesium salts were observed. Hydration from dissolution and 

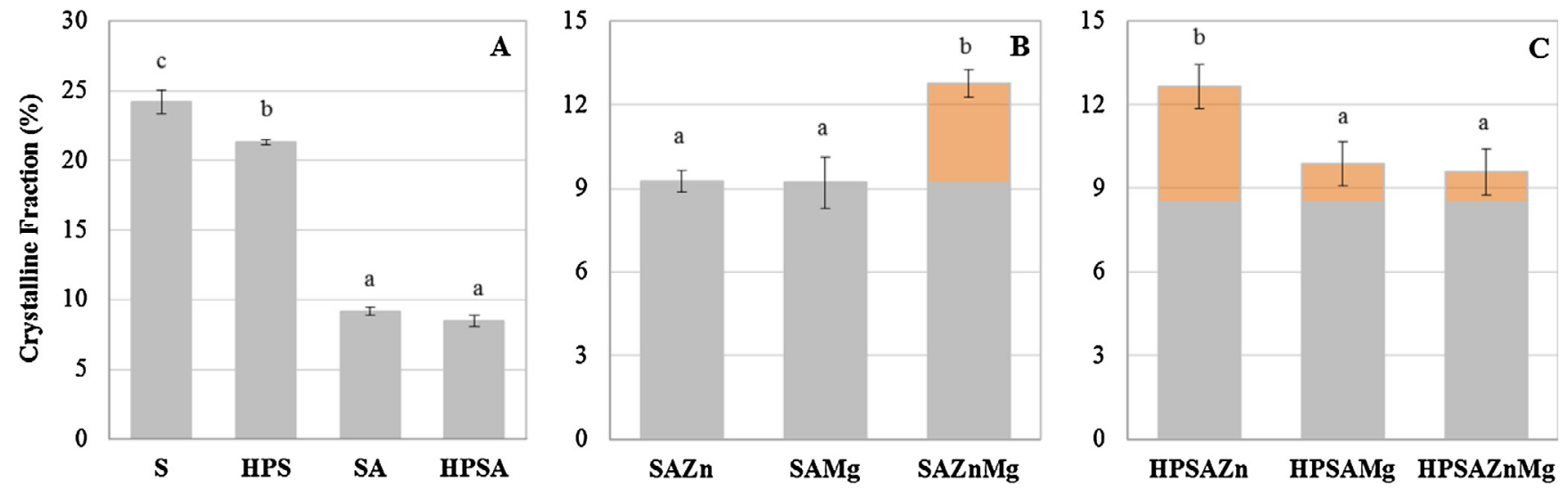

Fig. 4 - Crystalline fraction (\%) of starch carriers: (A) control carriers; (B) alkaline treated starches with minerals; (C) alkaline-high pressure treated starch with minerals. Orange portion in the column represents the mineral crystalline fraction of each sample, while grey portion represents the starch contribution. Different letters indicate statistical differences between samples in each frame (LSD, $\alpha=0.05, n \geq 3$ ). (For interpretation of the references to color in this figure legend, the reader is referred to the web version of this article.)

recrystallization of salt with different water content on the starch granule surface would have taken place during the treatment (Teixeira et al., 2015).

The crystalline fraction of starch carriers and active starches is shown in Fig. 4. For starch carriers without minerals, the crystalline fraction decreased in the following order: $\mathrm{S}>\mathrm{HPS}>\mathrm{SA}=\mathrm{HPSA}$, denoting that the partial gelatinization of the corn starch granules which occurred during the high pressure treatment was lower than the same phenomena under alkali conditions. These results agree with those of SF and their relationship with calorimetric studies is presented in the next section. The presence of mineral salts contributed to the overall crystalline fraction only in a few cases; $\mathrm{SA}_{\mathrm{ZnMg}}, \mathrm{HPSA}_{\mathrm{Zn}}$, $\mathrm{HPSA}_{\mathrm{Mg}}$ and HPSA $\mathrm{ZnMg}$, supporting the results showed in Table 1.

\subsection{Calorimetric studies of active starch carriers}

Differential Scanning Calorimetry (DSC) data for treated and untreated starch samples are shown in Fig. 5. Both enthalpy and peak temperature values reflect the global energetic changes in the thermal DSC process. In this case, it may include contributions not only resulting from starch gelatinization, but also others related to metal salts and their interaction with starch. Fig. 5A shows that alkaline and high pressure treatments proceed in different directions over starch gelatinization enthalpy. Alkaline treatment (SA), although partially destroyed starch granular structure, increased the enthalpy measured by DSC, while high pressure treatments (HPS) reduced the enthalpy of starch thermal gelatinization, reflecting the progress in the gelatinization process (Fig. 5A). This apparently contradictory observation could be a result of a compensation of different energetic processes, as the alkaline treatment could create additional charged groups (as mentioned before) which may give rise to new energy-rich hydrogen bridges, accounting for the extra enthalpy.

With regard to the starch gelatinization temperature, alkali treatment induced an increase in the peak temperature (Fig. 5A), may be due to its effect on smaller granules or to the stabilization granted by the newly created charged groups and hydrogen bridges (Lai et al., 2002). Meanwhile, HPS had a reduced gelatinization peak temperature. The effect of pressure treatment in the gelatinization temperature of the remaining non-gelatinized starch is controversial: some authors report decreases (Błaszczak et al., 2005; Knorr et al., 2006) while other found increases (Hibi et al., 1993; Muhr et al., 1982; Thevelein et al., 1981). The first case could be due to a general destabilization of the granule structure, while the second could work via a preferential gelatinization of the smaller and more unstable granules, leaving the more stable unaltered. According to Liu et al. (2008), lowered melting energy of the crystalline regions could be due to a partial melting of the crystalline structure during high pressure compression or an alteration of the crystalline structure. In the present work, results could confirm the partial destabilization of all starch granules, in good agreement with the increase in porosity and swelling ability of treated granules in comparison to native starch. Meanwhile, HPSA showed an intermediate behavior in both enthalpy and gelatinization temperature to SA and HPS (Fig. 5A), suggesting an intermediate character or a compensation of different effects, where the reduction in temperature and enthalpy associated to high pressure granular dissolution was moderated by the creation of new charged interactions.

About the effect of metal addition, a general observation could be that alkali treatments increased peak temperature for all samples, while their effect on enthalpy depended on the type of metal present (Fig. 5B-D). The differences in enthalpy for all the different treated samples with zinc were small (Fig. 5B). In a previous work, it was found that enthalpy was reduced over that of native starch without metals (Teixeira et al., 2015). Peak temperature of zinc bound samples, for pressure and alkali treatments, was higher than that for native starch. Meanwhile, samples with magnesium (Fig. 5C) kept a similar enthalpy level among treatments (and also similar to the zinc samples) except for the pressure treated starch (HPS) which showed a much reduced enthalpy, in agreement with previous observations (Teixeira et al., 2015). Peak temperature profiles for magnesium added samples were similar to that for zinc samples, at all treatments.

Fig. 5D shows that samples with both minerals presented a closer behavior in both enthalpy and peak temperature to magnesium added samples, than to zinc containing ones. In all cases the correspondence of both enthalpy and peak temperature to metal incorporated amount was not appreciated. The close details of the interaction starch-metal ion are not known. Different binding types can contribute to the general energetic balance in a different and opposite directions, giving rise to the overall calorimetric footprint. 

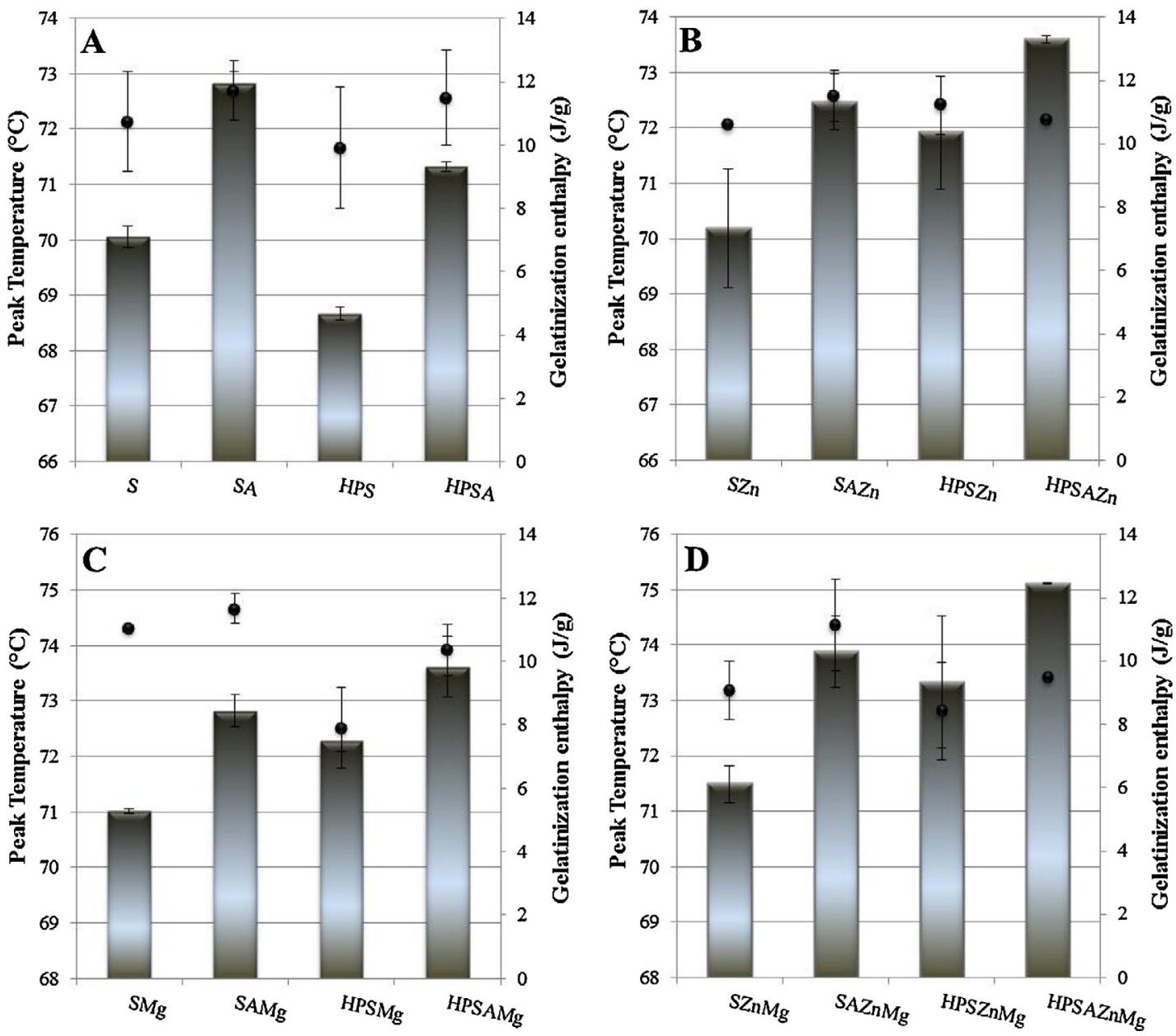

Fig. 5 - Calorimetric data of native corn starch (S), native-alkali treated starch (SA), high pressure treated starch (HPS) and high pressure-alkali treated starch (HPSA), alone (A) or with zinc (B), magnesium (C) or both minerals together (D). Main axis: peak temperature (dots). Secondary axis: gelatinization enthalpy (bars).

Although some works indicate the presence of sodium ions remaining in starch granule after alkaline treatment (Karim et al., 2008), in this case a competing or otherwise negative effect of the presence of these ions for the incorporation of minerals was not observed. Clearly, alkaline treated samples incorporate more metals ions that other samples, thus, the effect of the latter treatment was more likely centered in inducing changes in the binding groups or in creating new pores in starch suitable for metal incorporation without a competence by sodium.

\section{Conclusions}

Alkaline, HHP, and a combination of both treatments were applied to evaluate microstructural changes in native corn starch that could enable it to be used as a potential mineral binder. Alkali addition was more efficient in relation to the increase in binding of minerals; higher amounts of zinc and magnesium were loaded in SA starches, followed by both, HPS and the combined treatment. The main differences in treatments lied on the gelatinization extent, which was higher for alkali treatments than for HHP treatments, as supported by DSC, crystallinity and swelling power. When a high amount of mineral per gram of starch is wanted and gelatinized starch is needed, SA treatment would be the better choice, furthermore taking into account that it is the easiest procedure with the lower cost. HPSA showed an intermediate behavior between alkali and high pressure treatments, contrary to an expected synergic effect. However, it was the only treatment showing a bimodal pore size distribution, with a higher pore size of starch granules. The observed changes in the starch microstructure allow the incorporation of active compounds in the new pores and could broad the range of applications of these modified starches compared to the use of only one procedure (HHP or alkali addition). Thus, if cost-benefit analysis is justified, a combination of the treatments could offer an interesting processing route.

\section{Acknowledgements}

This work was carried out thanks to the project "APHENZ" (AGL2016-77056-R) from the Spanish MINECO, including FEDER funds.

\section{References}

Błaszczak, W., Fornal, J., Valverde, S., Garrido, L., 2005. Pressure-induced changes in the structure of corn starches with different amylose content. Carbohydr. Polym. 61, 132-140.

Beirão-da-Costa, S., Duarte, C., Moldão-Martins, M., Beirão-da-Costa, M.L., 2011. Physical characterization of rice starch spherical aggregates produced by spray-drying. J. Food Eng. 104, 36-42. 
Bock, C.W., Katz, A.K., Glusker, J.P., 1995. Hydration of zinc ions: a comparison with magnesium and beryllium ions. J. Am. Chem. Soc. 117, 3754-3765.

Buckow, R., Heinz, V., Knorr, D., 2007. High pressure phase transition kinetics of maize starch. J. Food Eng. 81, 469-475.

Considine, K.M., Kelly, A.L., Fitzgerald, G.F., Hill, C., Sleator, R.D., 2008. High-pressure processing - effects on microbial food safety and food quality. FEMS Microbiol. Lett. 281, 1-9.

Deladino, L., Teixeira, A.S., Navarro, A.S., Alvarez, I., Molina-García, A.D., Martino, M., 2015. Corn starch systems as carriers for yerba mate (Ilex paraguariensis) antioxidants. Food Bioprod. Process. 94, 463-472.

Drake, M., Harrison, S., Asplund, M., Barbosa-Canovas, G., Swanson, B., 1997. High pressure treatment of milk and effects on microbiological and sensory quality of Cheddar cheese. J. Food Sci. 62, 843-860.

Fernández, P.P., Sanz, P.D., Martino, M.N., Molina-García, A.D., 2008. Partially-gelatinised starches by high hydrostatic pressure as oligoelement carriers. Span. J. Agric. Res. 6, 129-137.

Fornal, J., Sadowska, J., Błaszczak, W., Jeliński, T., Stasiak, M., Molenda, M., Hajnos, M., 2012. Influence of some chemical modifications on the characteristics of potato starch powders. J. Food Eng. 108, 515-522.

Hayashi, R., 2005. In: Toriyama, K. (Ed.), Rice is Life Scientific Perspectives for the 21st Century. Int. Rice Res. Inst, pp. 278-280.

Hibi, Y., Matsumoto, T., Hagiwara, S., 1993. Effect of high pressure on the crystalline structure of various starch granules. Cereal Chem. 70, 671-676.

Huber, K.C., BeMiller, J.N., 2000. Channels of maize and sorghum starch granules. Carbohydr. Polym. 41, 269-276.

JCPDS-International Centre for Diffraction Data, A.r.r.P.v.

Jobling, S., 2004. Improving starch for food and industrial applications. Curr. Opin. Plant Biol. 7, 210-218.

Karim, A.A., Nadiha, M.Z., Chen, F.K., Phuah, Y.P., Chui, Y.M., Fazilah, A., 2008. Pasting and retrogradation properties of alkali-treated sago (Metroxylon sagu) starch. Food Hydrocoll. 22, 1044-1053.

Knorr, D., Heinz, V., Buckow, R., 2006. High pressure application for food biopolymers. Biochim. Biophys. Acta 1764, 619-631.

Lai, L.N., Karim, A.A., Norziah, M.H., Seow, C.C., 2002. Effects of $\mathrm{Na}_{2} \mathrm{CO}_{3}$ and $\mathrm{NaOH}$ on DSC thermal profiles of selected native cereal starches. Food Chem. 78, 355-362.

Li, W., Bai, Y., Mousaa, S.A.S., Zhang, Q., Shen, Q., 2012. Effect of high hydrostatic pressure on physicochemical and structural properties of rice starch. Food Bioprocess Technol. 5, 2233-2241.

Liu, Y., Selomulyo, V.O., Zhou, W., 2008. Effect of high pressure on some physicochemical properties of several native starches. J. Food Eng. 88, 126-136.

Mújica-Paz, H., Valdez-Fragoso, A., Samson, C.T., Welti-Chanes, J., Torres, J.A., 2011. High-pressure processing technologies for the pasteurization and sterilization of foods. Food Bioprocess Technol. 4, 969-985.

Maher, G.G., 1983. Alkali gelatinization of starches. Starch Stärke 35, 226-234

Molina-García, A.D., 2002. The effect of hydrostatic pressure on biological systems. Biotechnol. Genet. Eng. Rev. 19, 3-54.

Mondragón, M., Bello-Pérez, L.A., Agama-Acevedo, E., Betancur-Ancona, D., Peña, J.-L., 2004. Effect of cooking time, steeping and lime concentration on starch gelatinization of corn during nixtamalization. Starch Stärke 56, 248-253.
Muhr, A., Wetton, R., Blanshard, J., 1982. Effect of hydrostatic pressure on starch gelatinisation, as determined by DTA. Carbohydr. Polym. 2, 91-102.

Nagata, K., Okamoto, H., Danjo, K., 2001. Naproxen particle design using porous starch. Drug Dev. Ind. Pharm. 27, 287-296.

Nasehi, B., Javaheri, S., 2012. Application of high hydrostatic pressure in modifying functional properties of starches: a review. Middle East J. Sci. 11, 856-861.

Niemelä, K., 1990. Conversion of xylan, starch, and chitin into carboxylic acids by treatment with alkali. Carbohydr. Res. 204, $37-49$.

Nor Nadiha, M.Z., Fazilah, A., Bhat, R., Karim, A.A., 2010. Comparative susceptibilities of sago, potato and corn starches to alkali treatment. Food Chem. 121, 1053-1059.

Oh, H., Pinder, D., Hemar, Y., Anema, S., Wong, M., 2008. Effect of high-pressure treatment on various starch-in-water suspensions. Food Hydrocoll. 22, 150-155.

Papathanasiou, M.M., Reineke, K., Gogou, E., Taoukis, P.S., Knorr, D., 2015. Impact of high pressure treatment on the available glucose content of various starch types: a case study on wheat, tapioca, potato, corn, waxy corn and resistant starch (RS3). Innov. Food Sci. Emerg. Technol. 30, 24-30.

Pei-Ling, L., Xiao-Song, H., Qun, S., 2010. Effect of high hydrostatic pressure on starches: a review. Starch Stärke 62, 615-628.

Roberts, S.A., Cameron, R.E., 2002. The effects of concentration and sodium hydroxide on the rheological properties of potato starch gelatinisation. Carbohydr. Polym. 50, 133-143.

Spiess, M., Gruehn, R., 1979. Beiträge zum thermischen Verhalten von Sulfaten. II. Zur thermischen Dehydratisierung des $\mathrm{ZnSO}_{4}$ $7 \mathrm{H}_{2} \mathrm{O}$ und zum Hochtemperaturverhalten von wasserfreiem ZnSO4+. Zeitschrift für anorganische und allgemeine Chemie $456,222-240$

Sujka, M., Jamroz, J., 2007. Starch granule porosity and its changes by means of amylolysis. Int. Agrophys. 21, 107-113.

Tang, M., Liu, Q., 2012. The acidity of caustic digested starch and its role in starch adsorption on mineral surfaces. Int. J. Miner. Process. 112-113, 94-100.

Tauscher, B., 1995. Pasteurization of food by hydrostatic high pressure: chemical aspects. Zeitschrift für Lebensmittel-Untersuchung und Forschung 200, 3-13.

Teixeira, A.S., Navarro, A.S., Molina-García, A.D., Martino, M., Deladino, L., 2015. Corn starch systems as carriers for yerba mate (Ilex paraguariensis) antioxidants: effect of mineral addition. Food Bioprod. Process. 94, 39-49.

Tester, R.F., Morrison, W.R., 1990. Swelling and gelatinization of cereal starches. I. Effects of amylopectin amylose, and lipids. Cereal Chem. 67, 551-557.

Thevelein, J., Assche, J.V., Heremans, K., Gerlsma, S., 1981. Gelatinisation temperature of starch, as influenced by high pressure. Carbohydr. Res. 93, 304-307.

Walenta, K., 1978. Boyleite, a new sulfate mineral from Kropbach, southern Black Forest. Chem. Erde 37, 73-79.

Wang, S., Copeland, L., 2012. Effect of alkali treatment on structure and function of pea starch granules. Food Chem. 135, 1635-1642.

Wang, B., Li, D., Wang, L.-j., Liu, Y.-h., Adhikari, B., 2012. Effect of high-pressure homogenization on microstructure and rheological properties of alkali-treated high-amylose maize starch. J. Food Eng. 113, 61-68.

Weirong, Y., Huiyuan, Y., 2002. Adsorbent characteristics of porous starch. Starch Stärke 54, 260-263.

Yamamoto, H., Makita, E., Oki, Y., Otani, M., 2006. Flow characteristics and gelatinization kinetics of rice starch under strong alkali conditions. Food Hydrocoll. 20, 9-20. 